\title{
El papel de las potencias medias en la política internacional
}

CARSTEN HOX B RAD, es miembro del Departamento de Relaciones Internacionales del Research School of Pacific Studies, Australian National University. Autor del Iibro The Concert of Europe: A Study in German and British International Theory, 1815-1914, Longmans, Londres, 1970, ha dirigido la edición de Super Powers and Frorld Order, Australian National University Press, Canberra, 1971. Actualmente esta preparando una obra sobre las potencias medias $y$ su papel en Ia politica intcrnacional.

La mayor parte de la literatura sobre las relaciones internacionales se refiere a las grandes potencias. Tanto las obras antiguas como las modernas, y'a sean clescriptivas o analíticas, se concentran generalmente en los miembros clominantes del sistema de Estados $y^{\prime}$ prestan escasa atención a sus integrantes menores. En estos últimos años, el papel de las pequeñas naciones atrajo la atención de algunos académicos y se convirtió en el tema de varios libros. Esto se clebe en parte, quizás, a la proliferación de nuevos Estados en África y Asia, desde la segunda guerra mundial y en parte, sin duda, al establecimiento de cátedras de relaciones internacionales en los países pequeños de diversas regiones del mundo. Sin embargo, el papel que desempeñan los países que no son grancles ni pequeños en la politica internacional es todavía un tema comparativamente descuidado. Aunque se ha escrito mucho sobre los problemas y la política de algunas potencias medias en particular, existen muy pocos trabajos serios acerca de esos Estados como clase, o grupo. La mayor parte -no todos- de los artículos y simposios que tratan del papel de estas potencias $y^{\prime}$ que se han publicaclo en cliversos países -entre ellos Canaclá, Alemania Fecleral e Inclia- se caracterizan más por sus argumentaciones reiterativas que por su profundo valor académico ${ }^{1}$. Esto

${ }^{1}$ Entre las excepciones se debe mencionar la contribución tlel Dr. R. A. Mackay al libro editaclo por Harvey L. Dyck y H. Peter Krosby Empire and Nations. Essays in Honour of Frederic H. Soward, University of Toronto Press, 1969. E1 ensayo se titula "The Canadian Doctrine of the Middle Powers" $y$ critica algunas de las ideas canadienses acerca de las potencias medianas. 
puede aplicarse también a la literatura del siglo xrx sobre la materia. Es difícil precisar si los vacíos de esta literatura deben considerarse como advertencia o como estímulo para los estudiosos que deseen abordarla; podría ocurrir que la razón de que se haya dicho tan poco sobre la naturaleza y el papel de estas potencias fuese sencillamente que hay muy poco que decir; pero también podría suceder que las dificultades inherentes al estudio del tema hubiesen disuadido a los especialistas.

Hay algo previo al estudio del proceso político internacional desde el punto de vista de las potencias medias, y es que debe examinarse el sistema de Estados descle dentro. Quienes, siguiendo la tradición de Ranke, concentran su atención exclusivamente en las relaciones entre las grandes potencias, hoy superpotencias, tienen la ventaja de ocuparse de los actores principales, pero corren el riesgo de adoptar una visión algo olímpica de la política internacional. Hay ciertos autores modernos a los que podría hacerse algunos de los cargos de distorsión que se han hecho a los historiadores de siglos pasados que mostraban una tendencia acentuada a escribir solamente sobre emperadores, reyes y generales, ignorando los estratos más modestos de la sociedad. Por otra parte, quienes abordan el tema desde el punto de vista de los países pequeños tienen una seria desventaja. Por moverse entre los peones de la política internacional, entre los Estados que tienden a ser objetos, más que sujetos, por lo menos en los asuntos fundamentales, les resulta difícil comprender ciertos procesos que ocurren, por así decirlo, por encima de sus cabezas. Aunque presenta dificultades muy particulares, el nivel intermedio de la jerarquía del sistema de Estados, podría constituir un campo con ciertas ventajas para acercarse a algunos problemas principales de la vida internacional. Es el punto de convergencia de naciones viejas y abrumadas, exhaustas luego de siglos de poder político del más alto nivel pero ricas en experiencia $\mathrm{y}$ de jóvenes y enérgicos países, conscientes de sus posibilidades y llenos de ambición. Como el de las clases medias de la sociedad doméstica, es el escalón en que se unen aquellos que estuvieron alguna vez en la cumbre y los otros que se hallaban originalmente al pie de la escalera integrando ambos un solo grupo con aquellas potencias que llevan largo tiempo ocupando posiciones intermedias. Es un punto que parece muy apropiado para estudiar no sólo la estratificación social y la movilidad vertical de la sociedad internacional sino también la interacción política entre las diversas clases del sistema internacional.

A las naciones que ocupan este estrado se les ha llamado potencias medias o, con más frecuencia, potencias intermedias. En algunas ocasiones se ha dicho que el término "potencia intermedia" fue introducido por primera vez hacia fines de la segunda guerra mun- 
Oarsten Holbraad / El papel de las potencias medias en la politica internacional

dial, cuando Canaclá y otros países presionaban por alcanzar posiciones influyentes en las Naciones Unidas, que entonces estaban organizándose. Esto no es cierto. El término apareció en los escritos políticos de siglos anteriores, especialmente en los del xrx, cuando lo utilizaron en particular los autores alemanes. Sin embargo, en la literatura política alemana de comienzos y mediados del siglo XIx, Mittelmacht significaba varias cosas distintas. Algunos de aquellos autores, los que Iuchaban por la unidad germana, utilizaron esta palabra en el sentido de "Poder central". Ya en 1802, Herder la utilizó en este sentido:

(Uno) desearía a la corona de Prusia la mayor gloria y felicidad, puesto que... la situación ha cambiado tanto. Rusia se alza hasta alcanzar un poder que no se... preveía; Suecia está empobrecida; Polonia ha desaparecido. Las regiones oriental y del sur de Europa han cambiado también, iy de qué manera! Quizás deberíamos agradecer a la Providencia por hacer que... (Prusia), unida ahora a Austria... llegue a convertirse en una parte de esa gran potencia central (Mittelmacht) que debe ayudar a proteger al continente que forman todos los pueblos germánicos y los reinos del norte contra la subyugación por parte de naciones extranjeras...2

En este caso, Mittelmacht se aplicaba a una potencia situada geográficamente en el centro y no a un Estado que ocupase una posición intermedia en la estructura de poderes del sistema de Estados. En verdad, los hombres que aceptaban la idea de Herder, de una potencia germana de tipo medio, no pensaban en absoluto en términos de un Estado secundario, sino de un país lo bastante fuerte como para sostenerse entre Rusia, por el Este y Francia por el Oeste. Freiherr von Stein, Friedrich List, Freiherr von Bruck, Konstantin Frantz y los otros estadistas y escritores que apoyaban el llamado movimiento grossdeutsch deseaban unir todos los territorios germánicos para hacer que el centro geográfico de Europa fuese también su centro político. Pero, puesto que la idea de una potencia secundaria estaba muy lejos de sus mentes, cuando pensaron en el futuro de la Mitteleuropa, el particular uso que dieron a la expresión potencia media tiene escasa aplicación aquí.

El senticlo del término que me ocupa es el que se refiere a un Estado que tiene una posición intermedia, en una jerarquía basada en el poder; a un país más fuerte que las naciones pequeñas, aunque

"Citado de Henry Cord Meyer: Mitteleuropa in German Throught and Action 1815-1945, La Haya, Martinus Nijhoff, 1959, p. 9. 
más débil que los principales miembros del sistema de Estados. Con este sentido, la palabra tiene también una larga historia. Mucho antes del siglo xIx, incluso, pueden hallarse casos cle autores europeos que distinguian entre grandes, pequeñas y medianas potencias y especulaban sobre sus diversas características y significación ${ }^{3}$. Esta clasilicación de los Estados es por cierto distinta de la ordenación tradicional, que responde a formas de gobierno y rango de los gobernantes y que coloca a los imperios en el punto más alto, a las repúblicas en el más bajo y a los Estados regiclos por monarcas o príncipes en el medio.

EI adjetivo encerrado en esta expresión tuvo a menudo un doble significado. Se ha utilizado "Middle" para caracterizar a la vez un lugar intermedio en la jerarquía de poder de los Estados y una situación de centro geográfico o una posición media entre dos antagónicas. Algunas veces incluso, se ha agregado las dos últimas acepciones al significado original cle la palabra.

Fue en una de las primeras y más sustainciales contribuciones a una teoría de las potencias intermedias donde encontré "potencia media" utilizada en todos estos sentidos. En la obra Manuscript aus Sïd-Deutschland que causó verdadera conmoción en Alemania cuando se publicó con seudónimo en Londres, en 1820, Friedrich Ludwig Lindner, editor $y$ escritor liberal de Stutgart $y$ amigo íntimo del rey de Württemberg argumentó que los Estados pequeños y medios de la Confederación Germánica debian unir sus fuerzas y establecer una tercera potencia germánica, en lugar de dejarse dominar por Austria y Prusia. Debían hacerlo no sólo por su propio bien, sino porque también Europa necesitaba esa nueva potencia germana. Aún no se habia restableciclo el equilibrio de poder europeo trastornado por Napoleón, y hasta lograrlo, ni siquiera la disposición pacifista de los dirigentes de entonces podría asegurar una paz dura-

"Agradezco al profesor Martin Wight por llamarme la atención acerca de un escritor del siglo xvi que empleó el concepto de potencia media. En la obra Ragión di Stato, que apareció por primera vez en 1589 , Giovanni Botero se preguntaba si un imperio grande, mediano o pequeño tenía la mejor posibilidad de existencia. Al anotar las desventajas de los Estados grandes y pequeños, decía que los de tamaño mediano eran los que tenían más facilidad para mantenerse cohesionados: "Estados de tamaño mediano son los que perduran más, ya que no están expuestos ni a la violencia debido a su debilidad intrínsca ni a la enviclia debido a su grandeza; y su riqueza y poder, siendo ambos moderados, determinan que las pasiones, en consecuencia, sean menos violentas; la ambición encuentra menos apoyo $y$ la licencia menor provocación que en los Estados mayores. El temor a los vecinos los hace mesurados, e incluso en el caso de que el sentimiento despierte hasta llegar a la ira, son más fácilmente apaciguados y queda restauracla la tranquilidad (Giovanni Botero, The Reason of State, traducción de P. J. and D. P. Waley, Rare Masterpieces of Philosophy and
Science, Londres, Routledge and Kegan Paul, 1956, pp. 7-9.) 
dera. Integrada por diferentes Estados, Europa era como un cuerpo constituido por órganos. $Y$ así como un cueipo podría perecer si se extirpase alguno cle sus órganos, el sistema de Estados también poclría sufrir un colapso, al carecer del tipo de miembros adecuados. Para prosperar y sobrevivir, Luropa necesitaba cierto número de Estaclos de un tamaño especial. En general, señalaba Lindner, cuanto menor fuese su número, mayor sería el peligro para el sistema y menor la seguridad para cada Estado. Por otra parte, un número excesivo de pequeños Estados podía causar confusión y constantes fricciones. Los pequeños Estados eran también demasiado débiles para resolver los problemas de la civilización. Liste contemporáneo de Hegel señalaba que los grandes objetivos requerían de un gran poderío para su realización. Los Estados más útiles eran las potencias medias, guardianes del equilibrio de poder y garantes cle la paz de Europa y de la seguridad de las otras potencias.

"Si están situadas entre los grandes Estados, serán guardianes aún más cuidadosos $y^{\prime}$ serviciales. Sin embargo, por esa misma razón, no deben ser clemasiado pequeños, porque entonces, el enemigo los desbordaría, obligándoles a aunar fuerzas con él. En caso necesario, las potencias medias deberían ser capaces de repeler por sí mismas un ataque enemigo."

Polonía había siclo un Estado de ese tipo, pero ya no existía. Sólo Alemania podía llenar el vacío clejado por su eliminación ${ }^{4}$. Cada una de las grancles potencias tenía algo que ganar con lia creación cle una potencia germana media.

"Cada vez que las potencias gigantes se vean amenazaclas por un ataque injusto cleben poder confiar en la ayuda de las potencias medias, que tendrán que saber lo que les aguarda si el Estado más grancle perece"...

Austria estaría protegida a la vez de un intento expansionista ruso $y^{\prime}$ de un ataque de Francia. Prusia gozaría de los mismos beneficios. Aunque Rusia estaría resguardacla de una invasión francesa, Francia quedaría garantizacla contra Rusia. E Inglaterra clesearía seguramente contar con una potencia media en Europa que fuese capaz de ganarse el respeto de Rusia, Francia, Austria y Prusia y fuese to bastance fuerte como para impedir una participación del tipo de la de Polonia. Al ocupar el lugar que había correspondiclo a Polonia en el sistema de Estaclos, una potencia germana de esta clase mantenclría alejaclas a las grandes potencias entre sí y garantizaría de esa manera la paz de Europa ${ }^{5}$. Aquí, en un libro que tiene

"Publicación de George lerichson, seudónimo, Londres, Griphi, 1820, pp. $221-24$. rbial., pp. 223-29. 
150 años, encontramos la idea de un Estado que no sería solamente un Mittelmacht, sino también un Zwischenmacht, con un poderío que estaría tanto geográfica como estratégicamente en el medio y sería suficientemente fuerte para actuar como eficaz Estado amortiguador.

Hay obras más recientes que proporcionan ejemplos del uso del término potencia media simultáneamente en el sentido de posesión de una fuerza media y posición intermedia en un conflicto. Autores y políticos de diversos países de tamaño medio han relacionado la expresión a cada una de las clos grandes cuestiones que preocuparon al mundo en las últimas décadas: el problema Este-Oeste y Sur-Norte. Según el uso que se le ha dado en Canadá, por ejemplo, la expresión tuvo durante mucho tiempo el senticlo de país que está en situación de mediar o realizar otras funciones útiles en los conflictos entre Estados, particularmente en aquellos que surgen de la rivalidad entre Unión Soviética y Estados Unidos. En realidad, algunos de los autores que mayores aportes han hecho al pensamiento canadiense acerca de las potencias medias se han inclinado algunas veces a poner énfasis en la posición mediadora, más que en la fuerza media. Por ejemplo, cuando John Holmes, Director del Canadian Institute of International Affairs, presentó a la India de Nehru como un gran ejemplo de potencia media, no lo hizo tanto por sus fuerzas militares o sus recursos económicos, como en consideración a su activa diplomacia en el conflicto entre las superpotencias. El señor Holmes aceptó también la práctica de incluir, en la lista de las potencias medias en algunos textos, a países como Noruega, Irlanda y Túnez, sosteniendo que la actuación en la política internacional puede ser más importante que la simple existencia, con estadísticas de tipo intermedio ${ }^{6}$.

En algunos países de tamaño medio, que han sido menos activos que Canadá en cuanto a mediación y preservación de la paz, el término se ha relacionado en forma ocasional con el problema que se plantea entre las partes desarrollada y subdesarrollada del mundo. Sir Garfield Barwick, que era entonces Ministro de Relaciones Exteriores de Australia, dijo en 1964 que su país era una potencia media en más de un sentido.

"Lo es (una potencia media) en el sentido general en que se utiliza la expresión. Pero también tiene intereses comunes tanto con los países avanzados como con los subdesarrollados; en materia de riqueza lograda, permanece entre los poseedores y no-

"John W. Holmes, "Is there a Future for Middlepowermanship?", Canada Role as a Middle Power, ed. J. Kink Gordon, Contemporary Affairs, No 35, Toronto, The Canadian Institute of International Affairs, 1966, pp. 15-18. 
Carsten Holbraad / El papel do las potencias medias en la politica intermacional

poseedores. És al mismo tiempo un granero y un país altamente industrializado. Tiene un pasado europeo y está ubicado en íntima relación geográfica con Asia?."

La última frase pasó a ser tema de una alocución pronunciada por Sir Alan Watt, en Viena, en 1968, cuando era. Director del Australian Institute of International Affairs. Aunque evitó utilizar el término potencia media, citó la descripción de Australia hecha por Sir Carfield y lo calificó de país errante entre dos mundos, Europa y Asia ${ }^{8}$. Aquí podría detectarse una concepción implícita de potencia media, relacionada con un tercer tipo de problema: el planteado entre civilizaciones, que en este caso serían las de Oriente y Occidente.

Cada uno de estos cuatro dobles significados de la expresión se refiere a una concepción diferente del papel de las potencias medias. El Mittelmacht que es también un Zwischenmacht equilibra el sistema de Estados y mantiene la seguridad y la paz; la potencia media entre las partes de un conflicto internacional y mantiene la paz; el poder medio entre las naciones más avanzadas y las más atrasadas del mundo ayuda a llenar el vacío entre los países pobres y ricos; y la potencia media entre dos civilizaciones promueve la comprensión internacional. No resulta sorprendente que estas nociones, que son más bien halagadoras para las potencias intermedias, hayan sido elaboradas en países que se conciben a sí mismos como potencias medias que realizan precisamente aquellas funciones. $\mathrm{Si}$ deseamos examinar la conducta de los Estados de tamaño medio en la política internacional, sería aconsejable despojar al término potencia media de los diversos excesos ideológicos que le han atribuido sectores interesados $y$ definirlo simplemente como un Estado que es considerablemente más fuerte que la mayoría de las pequeñas naciones pero significativamente más débil que las grandes potencias. Sería más fácil entonces descubrir la forma en que esos Estados tienden realmente a comportarse en diversas situaciones y determinar si sus funciones difieren de hecho, y en lo fundamental, de aquellas típicas de las pequeñas naciones y de aquellas características de las grandes potencias.

Este criterio plantea inmediatamente problemas en cuanto a medir la fuerza de los Estados y decidir el punto en que deben trazarse las líneas divisorias en una jerarquía de grandes, medianas y pequeñas potencias. Algunos autores modernos interesados en los

${ }^{7}$ Current Notes on International Affairs, March, 1964 (Departament of External Affairs, Canberra), vol. 35, No. 3, p. 24 (IIouse of Representatives, 11 de marzo).

${ }^{8}$ Sir Alan Watt, 'Ost und West-Australien und die Probleme Südostasiens', Osterreichische Zeitschrift fiir Aussenpolitik, 9 Jahrgang, Heft 1, 1969, pp. 15-31. 
poderes medios han tratado cle elaborar criterios absolutos para clasificar a los Estados. El economista canadiense Erick Hanson agrupó y dividió a las naciones del munclo en relación con los niveles de ingresos y productividad per cápita y totales. Como muchos otros autores, pensó que el producto nacional bruto total era el mejor y más objetivo indicador del poderío de una nación, asumiendo que los factores que constituyen el poder; población, área, ubicación estratégica, organización institucional, liclerazgo y participación en las organizaciones internacionales, alianzas, asociaciones y zonas comerciales estarían mejor reflejadas en esta cifra estadística. Sin embargo, pensó que era necesario relacionar el PNB total con la población, debido a que el ingreso per cápita es muy importante en cualquier apreciación clel poderío. Su lista de las potencias medias se extendía descle las grandes hasta las pequeñas naciones e incluía a Canadá como la potencia media par excellence ${ }^{9}$. En un artículo sobre la India como potencia media, J. D. Sethi, director de Estudios del Indian Council on World Affairs, utilizó también un criterio económico para definir los poderes medios, pero redujo su número, haciendo una lista de sólo siete países en todo el munclo $\mathrm{e}$ introdujo la categoría de poderes medios potenciales. ${ }^{10}$

Cuando David Vital quiso excluir a las potencias medias de su estudio de las pequeñas naciones, titulado The Inequality of Slates (La Desigualdad de los Estados) definió muy en general los límites superiores de la clase de los pequeños Estados según su población: de 10 a 15 millones en los países económicamente desarrollados y de 20 a 30 millones en los subdesarrollados. Subrayó que estos límites, que pasaban así a convertirse en los que él establecía como inferiores para las potencias medias, eran muy arbitrarios. Por ejemplo, colocaba a Italia, México y Brasil en la categoría de potencias medias, pero dejaba a Australia entre las naciones pequeñas. ${ }^{11}$

Otros autores han definido a los poderes medios en relación a la capacidad para producir armas nucleares. Por ejemplo, William Schneider, del Fudson Institute, afirma que los poderes medios de las décadas del setenta y del ochenta serán,

"aquellas naciones industrializadas o semindustrializadas capaces de hacer una inversión de 10 a 20 billones de dólares clurante

\footnotetext{
'Eric Hanson, 'The Economic Policies of a Middle Power', Canada's Role as a Middle Power, pp. 102-04, y 108-10.

${ }^{10} \mathrm{~J}$. D. Sethi, 'India as Middle Power', India Quarterly, Vol. XXV, No 2, April-June 1569, pp. 10خ-108.

${ }^{11}$ The Inequality of States: A Study of the Small Power in International Relations, Oxford, Clarendion Press, 1967, p. 8.
} 
Carslen holbraad / IN papol de Jas potoncias modias en In politich intornacionul

un periodo de cinco a quince años para clesarrollar una fuerza nuclear significativa."12

Naturalmence, este criterio no toma en consideración las intenciones de cacla país estudiado.

El Forschungsinslilut der. Deulschen Gesellschaft für Auswärtige Politik, de Bonn, que publicó en 1969 un simposio sobre el papel de las potencias medias, adaptó un juicio diferente. Luego de un gran esfuerzo inicial por esbozar definiciones precisas para clistinguir las diversas clases de pocleres, descartaron la búsqueda de un criterio objetivo (así ocurrió con el Instituto de Política y Economía Internacional de Praga) y en cambio resolvieron definir a las potencias en términos cle la influencia que ejercen. Coincidieron en que un poder medio era "un Estado que desempeña un papel en su región".13

Ninguna de estas definiciones es clel todo satisfactoria. Cuando se las aplica, cada una cle ellas conduce a anomalías. En los criterios objetivos la clificultad reside no tanto en que producen demasiados casos marginales, como en que, en último término, las líneas divisorias resultan arbitrarias. La clefinición alemana plantea los problemas de resolver lo que significa desempeñar un papel y delimitar las regiones. Pero hay un argumento contra los tipos de clefinición mencionados aquí que resulta aún más importante, y es que su aplicación queda restringida a la política internacional contemporánea. Esto es verclad especialmente respecto al intento alemán de caracterización de los poderes medios. Mientras los límites expresados en términos de PNB, ingreso per cápita, población e incluso capacidad económica para desarrollar cierto tipo de arma podrían ajustarse para ser aplicados a otras situaciones históricas (suponiendo que se dispusiera de datos estadísticos) la elaboración de una clefinición relativa a la obra dentro de una región supone la existencia de un sistema internacional dividiclo en regiones, que es relativamente reciente. Aunque en siglos anteriores había algunas regiones del mundo aparte de Europa (América Latina, por ejemplo) en las que los Estados locales formaban un sistema propio, dichos Estados no formaban parte al mismo tiempo de un sistema global o central. Los poderes medios, ya fuesen europeos, como la Italia unida a fines del siglo xix, o latinoamericanos, no pueden ser definidos en términos de una función regional distinta a

${ }^{22}$ William Schneider, Jr., "The French Nuclear Force and the Economic and Strategic Prospects for Medium Powers Independent Nuclear Deterrent', Arms Control and National Securily, Col. I, 1969, p. 73, nota.

${ }^{13}$ The Role of Middle Powers in World Politics, Bonn, Forschungsinstilut der Deulschem Gesellschaft für Auswärtige Politik, 1968, p. 4. Edición alemana aparccida en 1969. 
la mundial. La definición alemana tiene además la desventaja de que relega a las potencias medias modernas a las regiones y prejuzga así, en cierta forma, una investigación sobre las funciones de tales potencias. Aunque podría muy bien ocurrir que los Estados de tamaño medio desempeñasen hoy un papel particularmente importante en sus regiones, no debiera excluirse la posibilidad de que tuviesen otras funciones en diversas situaciones de la política internacional y surgieran circunstancias en que se hallasen comprometidos en actuaciones globales o reducidos a una dimensión tan pequeña como la que es característica de los pequeños Estados.

No debe definirse exactamente en los mismos términos a una potencia media y a una grande. Un país es una gran potencia no sólo por haber alcanzado el más alto grado de fuerza militar y recursos económicos, sino también porque otros Estados le reconocen cierto status en la sociedad internacional. Pese a los diversos esfuerzos realizados desde hace tiempo para brindarles un reconocimiento, los pocleres medios no gozan de ninguna categoría formal semejante a dicho status. ${ }^{14}$ De allí que sólo pueda distinguírseles sobre la base de la fuerza que poseen y el poder que ejercen. Pero resulta extremadamente difícil apreciar esa fuerza y ese poder. Puesto que estas apreciaciones significan invariablemente adoptar ciertas alternativas personales y puesto que las divisiones que se basan en ellas tienden en último término a ser arbitrarias, hay algo que debemos señalar para poder apoyarnos clara y clecididamente en los métodos subjetivos que utilicemos para clasificar a los Estados en categorías inferiores a las de las grandes potencias. Cuando los Estados a clasificar son miembros de un sistema histórico en que el material estadístico es muy escaso, resulta incluso necesario recurrir a inétodos menos exactos.

Esto no quiere decir, por cierto, que, una vez dividiclos los Estados

${ }^{14}$ Pese a que España, Portugal y Suecia eran miembros del Comité de los Ocho, en el Congreso de Viena, no tenían status especial después de 1815. Tampoco lo tenía Holanda cuyo representante al Congreso de Viena, en años posteriores, defendió los derechos de España y Holanda para ser promovidos del rango de pequeñas potencias; finalmente, obtuvieron el rango de potencias intermedias. Ni las distinciones en representación al Congreso para La Paz de 1919, ni la práctica de reelección al Consejo, en los primeros años de la Liga de Naciones, condujo al establecimiento de potencias medias reconocidas. Y el principio llamado funcional, que fue invocado particularmente por Canaclá, cuando las Naciones Unidas estaban en proceso de organización, de acuerdo con el cual la pertenencia no permanente al Consejo de Seguridad es decidida de acucrclo a la capacidad para contribuir a la mantención de la paz, y la seguridad y cl status en los nuevos organismos económicos deberá ser determinado por consideraciones económicas, no fue ni amplia ni explícitamente aceptado como medida para garantizar un status especial para las potencias intermedias tanto militar como cconómicamente. 
sobre la base de impresiones subjetivas en grandes, medios y pequeños, no sea fructífero e importante, en la medida de lo posible, apoyar tal clasificación con un sistema de índices objetivos del tipo usado por los autores mencionados anteriormente. Pese a que dicho criterio mixto sin duda presentaría cierto número de problemas metodológicos, y sería motivo de algunas anomalías en su aplicación, bien podría ser la única forma para alcanzar clasificaciones fructíferas cuando se trabaja con material histórico contemporáneo.

Mi intención no es por cierto confeccionar listas de potencias medias, ya sean del pasado o del presente, ni tampoco llegar a la confección de una tipología o de un sistema satisfactorio de índices. Pero antes de proseguir la discusión de los papeles de las potencias medias con particular referencia al sistema internacional vigente, es necesario indicar en forma escueta las posiciones en que se encuentran los límites inferior y superior de las potencias medias respecto de las otras categorías en la jerarquía moderna de los Estados; en otras palabras, cuáles son las potencias que constituyen el tema de la discusión. En un sistema predominantemente dualístico, como el que existió durante las décadas de 1950 y 1960, la demarcación superior se situaría justamente por debajo de la línea de las potencias principales. Como el nombre mismo lo indica, los Estados Unidos y la Unión Soviética se encuentran ahora en la categoría de superpotencias. Ya que ellas son las únicas en el mundo moderno que en efecto son superpotencias, en el sentido clásico del término, la distinción entre ellas y las potencias secundarias, aquellas potencias mayores y que en cierta época fueron superpotencias, parece tener mucho más significación que la división entre las últimas y aquellas localizadas inmediatamente por debajo de ellas. En la situación actual de la política internacional, el caso marginal de la República Popular China, que se encuentra más bien por encima, y que aparentemente está viviendo un proceso de transición de potencia media a superpotencia, calificar a esta nación como superpotencia en ciernes o como una superpotencia media depende en gran medida de la perspectiva desde la cual se la enfoca. Los casos marginales inferiores son más numerosos y tal vez quedarían incluidos Estados como Indonesia, Pakistán, México y la República Arabe Unida. Algunos de estos países cle rango marginal pueden ser descritos como potencias medias en ciernes. La docena o más de países que se encuentran entre el nivel más alto y el más bajo puede ser dividida en dos categorías: una que comprende ex grandes potencias: Gran Bretaña, Francia, la República Federal Alemana y Japón, y otra que incluye tanto aquellos países que vienen gozando desde algún tiempo atrás del status de posición media, como por 
ejemplo Brasil e Italia, $y$ aquellos que no hace mucho han ascendiclo a tal rango, como Canadá, India, África del Sur y otros.

Toda la jerarquía es más bien similar al sistema de clases británico, es clecir con unos cuantos aristócratas a la cabeza, una numerosa clase trabajadora en la base de la pirámide y en el centro, una clase media superior, media y baja, con un número considerable de casos marginales. Como en Gran Bretaña, aquellos que se encuentran en el nivel inferior del sector intermedio, los que están ansiosos de mejorar su situación o temerosos de descender aún más hasta entrar en la clase más baja, son los que tienen más conciencia del status medio y por consiguiente están decididos a exigirlo. Mientras que los que pertenecen a la categoría "no elevada" se inclinan a insistir en la distinción entre ellos y los que se encuentran a nivel más bajo de la escala de la sociedad, los miembros de la clase media alta en algunas ocasiones tienden más bien a hacer difusa la clivisión entre ellos y los que se encuentran por encima.

El papel de las potencias medias puede ser examinado de acuerdo con dos sistemas básicos de la política internacional: el dualístico y el múltiple. En el dualístico, o bipolar, los diferentes tipos de relación posible entre las dos potencias principales pueden ser concebiclas como un espectro, con la guerra en un extremo, y el condiminio, en el otro. Entre los extremos se encuentran, próximos a la guerra, los varios estaclios cle la guerra fría; próximas al condominio, hay relaciones de cooperación que constituyen casi un gobierno conjunto; $y$, en el medio, una gama amplia, algunas veces llamada détente, constituida por varias combinaciones de rivalidad y cooperación, y de la cual la actual situación internacional es un ejemplo. El espectro está clefinido de acuerdo con el nivel de tensión y el grado de control de la misma entre las dos potencias. La guerra marca el punto más elevado de la tensión y un grado bajo de control; el condominio señala la situación opuesta y la guerra fría, la détente y la cooperación constituyen posiciones intermedias. Cada uno de los tipos de la relación clualística encierra peligros muy particulares y ofrece oportunidades a los otros miembros del sistema cle Estados; pero en este trabajo sólo se han de considerar los tres tipos más relevantes en la política internacional de las dos últimas décadas, es decir: la guerra fría, el condominio y la détente. En cada caso se ponen de manifiesto las reacciones de las potencias medias frente a los problemas que encaran y su comportamiento 
internacional puede ser comparado con aquel de las pequeñas naciones.

En una situación de guerra fría, las potencias medias, conjuntamente con la mayoría de los otros miembros del sistema de Estados, enfrentan dos grandes peligros: convertirse en víctimas de la rivalidad central y ser objetos de usurpación e incluso ser devoradas por uno de los rivales, y que la guerra fría se transforme en una guerra total en la que todo el mundo se hallaría envuelto. Las potencias medias, como los Estados más pequeños, pueden reaccionar en diversas formas. En la guerra fría de los últimos años de las décadas de 1940 y de 1950, la mayoría de las potencias medias, atrapaclas entre la Unión Soviética y los Estados Unidos y expuestas a la presión de ambas naciones, concertaron alianzas militares con aquella potencia con la que tenían mayor afinidad y en contra de la que más temían. No sólo las potencias medias del nivel más elevado, como Canadá y Australia, tomaron este mismo camino. Unas cuantas, que generalmente se encontraban algo alejadas del centro de tensión entre el Este y el Oeste, fueron capaces cle acloptar una posición de equilibrio entre los clos bandos. India es un ejemplo prominente cle aquellas potencias que optaron por el no alineamiento. El papel que desempeñan las potencias alineadas, en tales circunstancias, difiere claramente del cle aquellas no alineadas. El Canaclá dejó ver ocasionalmente que en ciertos momentos, como aliado y vecino de los Estados Unidos, ha empleado cierta influencia restrictiva en las relaciones de su socio mayor con el lado opuesto; y, sin cluda adguna, Gran Bretaña, así como otros miembros secundarios de la alianza occidental, ha actuado similarmente en muchas ocasiones. Pero decir que la influencia de las potencias medias en tales situaciones siempre tiende a moderar la política y las actitudes del miembro prominente de la alianza sería alejado de la realidad. Parece más posible, por ejemplo, decir que Polonia y la República Democrática Alemana, en 1968, presionaron, o por lo menos alentaron, a la Unión Soviética en su invasión a Checoslovaquia. Un estudio detaIlado de la conducta de las potencias medias en las alianzas de la guerra fría bien podría clarificar en qué clase de situaciones estarian ellas capacitadas para reducir la tensión entre las dos potencias prominentes de las alianzas y en qué circunstancias tenderían a exacerbar la tensión. Cualquiera que fuese la naturaleza de la influencia ejercitada por clichas potencias medias, es muy posible que el papel que desempeñan en las alianzas difiera sustancialmente del característico de los miembros pequeños de la alianza, que podrían encontrarse frente a los mismos peligros y tener preocupaciones similares pero a los cuales los dirigentes de la alianza pueden prestar menor atención. 
Entre los caminos abiertos para las potencias no alineadas en situaciones de guerra fría está el de tratar de interceder en la rivalidad central y formular ciertas medidas de conciliación. Para dichas potencias una guerra fría significa no sólo peligros sino también oportunidades. Aunque la posibilidad de que la tensión entre las potencias principales escape a todo control, significa un gran peligro, tanto para ellas como para todo el mundo, también es cierto que un alto grado de tensión no del todo incontrolada en la correlación central les suministra ciertas ventajas. Guando los protagonistas y sus aliados se hallan encerrados en una competencia feroz pero reprimida, el campo cle acción de las potencias no comprometidas tiende a ser más amplio. Al ofrecer sus buenos oficios a los principales rivales como lo hizo Nehru clespués del estallido de la guerra de Corea, por ejemplo, esas potencias medias pueden hacer todo lo posible para contener los conflictos locales y evitar la guerra, sacando al mismo tiempo el máximo de beneficios que puedan derivarse de la existencia de la guerra fría. Este último podría sèr el resultado más sustancial de su acción. En una guerra fría entre dos grandes potencias, a las potencias secundarias les resulta muy difícil mediar para intentar la conciliación. Pero, al intentarla, pueden mejorar su condición diplomática y fortalecer su posición internacional. De esta manera, puede argumentarse que el verdadero resultado de los esfuerzos diplomáticos de Nehru durante la década del 50, cualquiera que fuesen sus motivos, fue no tanto reducir la tensión entre Oriente y Occidente como situar a la India en una posición de líder de los países no alineados y vocero del Tercer Mundo. La situación de guerra fría tiende también a mejorar la posición y la perspectiva de los pequeños países no comprometidos. Pero, cualquier país de esas características que resolviera asumir el papel de mediador potencial en el conflicto principal tendría probablemente menos influencia que una de las potencias medias predominantes y por consiguiente obtendría menos ventajas de ese papel.

Aunque la guerra fría dentro de un sistema dualista tiende a hacer en magnitud el campo de acción de las potencias medias, el condominio -es decir el gobierno conjunto, o por lo menos un alto grado de control consensual ejercido por las dos grandes potencias en la sociedad internacional- generalmente restringe agudamente la libertad de todos ellos. Un acuerdo de condominio tiende a reducir a los otros miembros clel sistema de 巨stados, tanto a los pequeños como de los medios, en objetos del proceso político internacional. El hecho de que el condominio, concepto diferente del de cooperación limitada, sea más bien un fenómeno raro en la política internacional, determina la dificultad para descubrir cómo han de 
reaccionar las potencias medias ante dicho fenómeno. Pero las relaciones internacionales de la década de 1960, que parecen presentar ciertas tendencias hacia a un condominio limitado de superpotencias, nos proporcionan algunos indicadores. Por ejemplo, una de las reacciones de Mao frente a la "colusión" ruso-norteamericana fue adelantar lo que posteriormente se ha llegado a conocer como "Ia doctrina de la zona intermedia", de acuerdo a la cual se permitiría a China comunista - país que en un mundo dominado conjuntamente por las dos superpotencias figuraría como una potencia media- cooperar temporalmente con algunos de los Estados capitalistas secundarios, tales como Gran Bretaña y Francia. Asimismo, el intento de las superpotencias de imponer el tratado de no proliferación nuclear a otros Estados, aparentemente indujo a algunas potencias medias, como la República Federal de Alemaniá y el Japón en particular, a hacer consultas mutuas y explorar las posibilidades de una respuesta conjunta. A nivel individual, se puede observar que algunos de los más decididos partidarios de la cooperación entre potencias medias, ya sean éstas locales o globales, en años recientes, se encontraron entre aquellas naciones que tenían el mayor temor frente al establecimiento de algún tipo de condominio informal por parte de las superpotencias.

La historia de la Confederación Germánica del siglo xIx, apoya hasta cierto punto la impresión de que el condominio en un sistema dualístico que alienta a las potencias medias a explorar las posibilidades de cooperar para oponerse a las potencias principales. En el período de restauración posterior a las guerras napoleónicas, las dos grandes potencias, Austria y Prusia, llegaron casi a ejercer un condominio basado en el principio de Metternich del "dualismo pacífico" en el sistema de Estados germánicos. Durante esa época, muchos estadistas y escritores (entre ellos Lindner) de algunos de los llamados "Estados medios" - Bavaria, Wüurtemberg, Baden y Hanover- desarrollaron la idea de una confederación dentro de otra confederación, cuyo objetivo principal sería oponerse a la hegemonía austro-prusiana en Alemania. Sin embargo; Ia incapacidad de estos Estados medios de entonces, y de los años posteriores de la Confederación, por allanar sus diferencias y unificar sus esfuerzos demuestra cuán débil es la posibilidad de cooperación entre las potencias medias contra la dominación de las grandes potencias. La dificultad que presenta el establecimiento de un condominio eficaz de dos grandes potencias se ve aparentemente aparejada por una dificultad aún mayor para establecer y mantener un acuerdo efectivo entre un grupo de potencias medias. Si esto es aplicable a un, sistema de Estados, geográficamente limitado y culturalmente homogéneo, como fue la Confederación Germánica, es muy posible que 
sea válido para un sistema global. Solamente el más represivo de los tipos de condominio podría obligar a todas las potencias medias a concertar un acuerdo.

Empero, cualquiera que fuese la habilidad que tuviesen las potencias medias para entrar en un estado de cooperación activa y cualquiera que fuese su capacidad para resistir a las grandes potencias, la actitud que adopten frente a los intentos de una dominación conjunta por parte de estas últimas sería del todo distinta a la que habrían de adoptar los Estados pequeños. La preocupación de las potencias medias, frente a dicho desafío, tiene que estar centrada en el problema que significa evitar el ser reducidas a la categoría de naciones débiles e impotentes. Los pequeños Estados tendrían, relativamente, mucho menos que perder frente a un arreglo de condominio y, por consiguiente, se esperaría que ellos no se opusiesen tanto a tal arreglo como las potencias medias. Si los países pequeños pensaran que algunas de las potencias medias significan una amenaza mayor que la de las grandes potencias, incluso podrían dar la bienvenida a tales medidas conjuntas y las apoyarían siempre que dichas medidas lograsen reprimir a las potencias medias. En la Confederación Germánica, por ejemplo, muchos de los Estados pequeños se inclinaron por el apoyo a Prusia contra los Estados medios, que eran sus enemigos tradicionales. $Y$ el tratado de no proliferación nuclear puede ser considerado no sólo como un ejercicio de condominio, sino también como una alianza de las potencias nucleares principales, incluida Gran Bretaña, por un lado, y las pequeñas naciones del mundo, por el otro, en contra de las potencias medias que se encuentran en un proceso de desarrollo nuclear o se proponen intentarlo en el futuro. Visto como un todo, las potencias pequeñas, generalmente sin mucho que perder y teniendo frecuentemente mucho que ganar del control de la política internacional por las grandes potencias, es muy posible que estén más dispuestas que la mayoría de las potencias medias a negociar parte de su independencia nacional a cambio de cierto grado de orden internacional. Es muy posible que cualquier oposición a los intentos de las grandes potencias de formar un condominio nazca de las potencias medias, pero también puede ocurrir que éstas actúen separadamente para protestar individualmente, y no resistan conjuntamente.

Las situaciones dualísticas, que se caracterizan por una mezcla de rivalidad y cooperación, son más complejas que la guerra fría y el condominio, y presentan una gama mucho más amplia de posibilidades para las potencias medias. Una de estas posibilidades consiste en concertar fórmulas de cooperación limitada con las dos grandes potencias y convertirse en socios menores y representantes de estas 
dentro de un conglomerado presidido por las dos grandes potencias o transformarse en agentes locales de las potencias principales. Esta posibilidad requeriría un grado relativamente alto de cooperación entre las grandes potencias. Sin ella, resultaría difícil comprometer a las potencias medias en un acuerdo o emplearlas conjuntamente como sus agentes en las relaciones con Estados más pequeños. Tal camino también presupondría una disposición de parte de las grandes potencias para desempeñar algún papel administrativo en el sistema político internacional y compartir algunas de sus responsabilidades con las potencias mayores secundarias. En la clécada de 1960, algunos estadistas y escritores, muy particularmente de Occidente, se pronunciaron por la cooperación más amplia entre las superpotencias y algunas de las situadas en un nivel inmediatamente inferior de la jerarquía, idea que comprometería a países tales como Gran Bretaña, Francia y el Japón en los esfuerzos desplegados para la solución de los problemas internacionales.

Si las dos potencias principales, en un sistema dualístico de este tipo, estuviesen incapacitadas o no deseasen tomar parte en la cooperación con las potencias medias, éstas no podrían desempeñar el papel correspondiente en la administración central de la política internacional. Pero las tareas y funciones regionales aún permanecerían abiertas para ellas. Por cierto, el desarrollo de la situación internacional existente en el sentido proyectado por Sisir Gupta en sus trabajos acerca de las relaciones entre las grandes potencias y el Tercer Mundo posiblemente ha de dejar un amplio campo de acción a algunas de las potencias medias. Al distinguir entre el mundo "interior" y el "exterior", expresa el temor de que las dos superpotencias lleguen a verse de tal manera absorbidas por sus propias relaciones actuales de cooperación limitada y competencia restringida que se encuentren tentadas a dedicar su atención exclusivamente a las áreas desarrolladas clel mundo, dando la espalda a las regiones periféricas. ${ }^{15} \mathrm{Si}$ los Estados Unidos y la Unión Soviética se concentraran exclusivamente en sus relaciones con Europa y Medio Oriente y dejaran la mayor parte del resto del mundo a su propia suerte, las potencias medias fuera de las regiones de América del Norte y Europa podrían hallarse ante una gran variedad de funciones a desempeñar. En algunas regiones, y bajo ciertas circuns-

${ }^{15}$ Respecto a este particular, resultan de interés los siguientes artículos del profesor Gupta: 'The Third World and the Great Powers', The Annals of the American Academy of Polilical and Social Science, November, 1969, pp. 54-63; 'Towards a New Political System in Asia', Meanjin Quarterly, July-September, 1969, pp. 340-48; 'Some problems of Asian Security', India: Studies in Social and Political Development, 1947-67, ed. A. Appadorai (Bombay, Asia Publishing House, 1968); e 'India and the Future in Asia,' India, Japan, Australia: Partners in Asia?, ed. J. D. B. Miller (Canberra, Australia National University Press, 1968) . 
tancias, una potencia media podría asegurarse una posición dominante y convertirse en gran potencia local. India en Asia meridional, África del Sud en Africa, y, tal vez en menor grado, Brasil en América Latina, son algunos ejemplos. En otras regiones, o bajo otras circunstancias, dos o más potencias medias podrían entablar relaciones no muy disímiles de aquellas que alcanzaron las superpotencias. Es muy posible imaginar, por ejemplo, una rivalidad entre Ghina y Japón en el Lejano Oriente y Asia suroriental, o entre India y Pakistán en el subcontinente, en la que los rivales centrales tendrían aún menos control que el que han podido tener en el conflicto entre Israel y la República Arabe Unida, en el Cercano Oriente. Tampoco clebería excluirse la posibiliclad de cooperación entre dos o más potencias medias regionales para establecer un acuerclo local por encima de las pequeñas naciones vecinas o tomar la iniciativa en labores regionales conjuntas, las cuales también comprenderían a los pequeños Estados de la región. Por consiguiente, en condiciones favorables, podría esperarse un renacimiento de la idea de cooperación entre India, Japón y Australia en la región asiática.

Los diversos tipos de papeles que pueden estar abiertos a las potencias medias en una détente dualista -como socios o agentes de las grandes potencias y como dirigentes locales, rivales o asociados- no son necesariamente excluyentes. Por ejemplo, algunas de las potencias medias pueden edificar una correlación cooperativista con las grandes potencias; otras pueden hallarse comprometidas en una rivalidad local. En años recientes, hemos sido testigos, en el Medio Oriente, de un entendimiento diplomático entre las dos superpotencias y Francia e Inglaterra, las dos potencias intermedias superiores, para tratar de administrar o controlar un conflicto regional entre dos potencias medias inferiores: la República Árabe Unida e Israel. Podrían presentarse igualmente otras mezclas de posiciones similares.

El Instituto de Investigación de Bonn define a las potencias medias en términos de su papel regional; algunos canadienses, en la actualidad, prefieren emplear la expresión "potencia regional" a la de "potencia media" establecida descle hace mucho tiempo; y un cierto número de escritores indios especulan acerca del rol futuro de las potencias medias en las regiones "periféricas" del mundo; todos estos conceptos son algunos de los muchos síntomas de que el papel de las potencias medias en un futuro cercano, será según se espera esencialmente regional. Si esta predicción resulta verdadera, lo que parece muy probable, las potencias medias más interesantes, en los próximos años, han cle ser con toda probabilidad las clel continente asiático. Las potencias medias europeas, en ambos lados de la división Este-Oeste, se encuentran tan cercanas al centro de 
tensión entre las superpotencias, como partes del mundo "interior", que su conducta internacional, cualquiera que fuesen las iniciativas que llegasen a tomar en los próximos años, ha de estar circunscrita a la correlación existente entre los Estaclos Uniclos y la Unión Soviética. De igual forma, la participación de las superpotencias en el conflicto del Medio Oriente tiende a restringir el campo de acción de las potencias medias locales y a preservar el estado de rivalidad entre Israel y la República Árabe Unicla y sus aliadas. Las potencias medias latinoamericanas se encuentran tan firmemente establecidas dentro de la esfera de interés norteamericano que la libertad de acción internacional que ellas tengan, tanto en el hemisferio como fuera de él, parece que ha de permanecer restringida por la hegemonía regional de los Estados Unidos. Canadá - "una potencia regional dentro de una región"- tan consciente como cualquiera de las otras acerca de las posibilidades subyacentes de las potencias medias, muy probablemente esté destinada a ser absorbida cada vez más en sus relaciones por su gigantesco vecino. Las potencias medias africanas en ciernes aún se encuentran en proceso de establecerse como naciones en un sistema regional de naciones, que apenas ha sido establecido. El papel que Africa del Sur pudo haber desempeñado se ha visto dificultado, $y$ a veces completamente imposibilitado, por la oposición de los Estados africanos y otras naciones, y esto debido a la política interna de dicha nación. Sin embargo, Japón, India, Pakistán, Indonesia y Australia, menos limitadas que muchas y más capaces que otras, disponen de un amplio campo de acción en las regiones del Pacífico y Asia y bien pueden asumir nuevos papeles en la política internacional del futuro. Cuál será el tipo de relaciones que han de establecer entre ellas, con China, con las superpotencias, y con los pequeños listados de la región, es aún materia especulativa y no de análisis.

En el sistema múltiple, o multipolar, de la política internacional, será necesario contrastar dos situaciones características. Una, que podría ser llamada la situación de concierto, está tipificada por un alto graclo de cooperación entre las grandes potencias; la otra, que podría llamarse situación de equilibrio de poder competitivo, se caracteriza por una aguda rivalidad. Como ejemplo de la primera situación podemos citar la política europea entre 1814 y mediados del siglo xrx, época en la que cinco grandes potencias, o sea la mayoría de ellas, habitualmente se consultaban frente a los problemas que surgían, y en algunas oportunidades coordinaban su política y uniformaban sus conductas para la solución de dichos problemas. A esta altura, es necesario hacer una distinción entre el acuerdo formal de la década de posguerra, generalmente conocido como el sistema de congreso, y el acuerdo mucho más infor- 
mal de las siguientes décadas, que funcionó a través de conferencias de embajadores ad hoc, y en ocasiones, por medio de contactos menos formales. Un acuerdo formal como el que normalmente sigue a un período de guerra general, refleja un más alto grado de consenso entre las partes que un acuerclo informal. El equilibrio de poder competitivo quecla ejemplarizado por la política europea de la segunda mitad del siglo pasado, antes de 1914, cuando la tensión cada vez más aguda hizo que las cinco principales potencias concertaran alianzas hostiles y condujo a poner en práctica una diplomacia, que según palabras de Bismark, consistió en reducirse a trois. Este tipo de situación puede variar desde una tensión restringida entre varias partes, situación que caracterizó la mayor parte del período inicial del siglo $x \mathrm{x}$, hasta la rivaliclad abierta entre dos alianzas opuestas que caracterizó la última década, o las últimas dos, antes de 1914, y que culminó con la Primera Guerra Mundial.

En situaciones de acuerdo, las potencias medias se hallan frente a condiciones más bien diferentes de aquellas que podrían gozar en situaciones más competitivas de un sistema múltiple. A juzgar por la historia del Acuerdo de Europa, un acuerdo, especialmente del tipo formal, ofrece las posibilidades menos halagüeñas a las potencias medias. Las tres potencias que, como miembros del Comité de los Ocho, en el Congreso de Viena, clisfrutaban de cierto tipo de posición intermedia en el sistema de posguerra -España, Portugal y Suecia- poco tiempo después fueron excluidas de todas las negociaciones importantes, tanto en Viena como en los congresos europeos subsiguientes. La solidaridad entre las grandes potencias, de la cual, en ciertos aspectos, se le hizo copartícipe al ex enemigo, obligó a las tres potencias secunclarias a descender al rango de pequeños Estados. Excepción hecha de alguna protesta ocasional respecto del trato injusto, sus opiniones no fueron escuchadas hasta el período de la posguerra. En la medida en que duró el estado de acuerclo, Europa se hallaba constituida por grandes y pequeñas potencias no existiendo, por lo tanto, potencia intermedia alguna. Sólo cuando Ia solidaridad de las cinco grandes potencias llegó al colapso, las potencias secundarias tuvieron la oportunidad de hacerse presentes, en mínimo grado, por cierto, desempeñando papeles menores en el sistema europeo. En 1834, por ejemplo, cuando las dos monarquías constitucionales de Occidence se vieron confiontadas por la Santa Alianza formada por tres soberanos autócratas del Este, España y Portugal aceptaron el papel de socios menores de Gran Bretaña y Francia en la Nueva Alianza cuádruple. Un estado de acuerdo múltiple, como el de un condominio dualístico, tiende a restringir la libertad de acción de las potencias medias y, por con- 
siguiente, eliminar la distinción entre ellas y las pequeñas potencias del sistema.

Las situaciones de equilibrio de poder competitivo generalmente dejan un mayor campo de acción a las potencias medias, lo cual hace mucho más difícil la generalización de la parte que han de desempeñar dentro del sistema internacional. La conducta del Imperio otomano y la unificación cle Italia, en el sistema europeo de postrimerías del siglo $\mathrm{xIx}$, pueden servirmos de puntos de referencia de los papeles característicos de las potencias medias en tales situaciones. Pese a que en el Congreso de París de 1856 el Imperio otomano fue formalmente admitido en el Acuerdo de Europa, y a que en la Conferencia de Londres de 1867 sobre la cuestión de Luxemburgo, Italia fue incluida en las reuniones de las grandes potencias, estos dos Estados, en muchos aspectos, se encontraban en situación tan inferior frente a las potencias principales, que de hecho bien podían haber sido considerados como potencias medias. Cuandọ la tensión entre ellas se agudizó en grado sumo, las grandes potencias tuvieron la oportunidad, en ciertas ocasiones, de desempeñar un papel importante en el equilibrio de poder en Europa, ya sea como socios menores en alianzas concertadas entre dos o tres grandes potencias, como fue el caso del Imperio otomano en la alianza de Crimea y de Italia en el sistema de alianza de Bismark, o adoptando una posición de equilibrio entre los dos grupos opuestos de grandes potencias, como fue el caso cle Italia en las dos décadas previas a la Primera Guerra Mundial. La historia del Imperio otomano sugiere otras posibles funciones para las potencias medias en un sistema de equilibrio de poder competitivo. Ocasionalmente, cuando la rivalidad entre las grandes potencias revistió el carácter de agudo $y$ el consenso entre ellas era ínfimo, las potencias medias fueron capaces de adoptar una línea común respecto de la Guestión de Oriente; de ahí que Turquía pudo resistir la presión de las potencias, induciendo a éstas a situarse en campos opuestos. En la medida en que ellas tuvieron éxito en prevenir todo tipo de intrusiones de parte de las grandes potencias, el Imperio otomano estaba, en efecto, elevándose hasta alcanzar el nivel de las grandes potencias y actuando, por consiguiente, como tal. Pero cuando la rivalidad entre las grandes potencias adquirió una forma diferente, Turquía se vio en una posición tal que hubo de encarar un clesafío desde otro ángulo. En 1912, cuando las cinco grandes potencias se halla. ban divididas en dos grupos de oposición hostil, los pequeños Estados balcánicos vieron la oportunidad de actuar en conjunto contra el país que tan a menuclo, en el pasado, había disfrutado de la protección conferida por el Acuerdo de Europa. Concertaron una liga, declararon la guerra a Turquía y la ganaron. Por tanto, el 
imperio otomano, que por largo tiempo había sido el objeto de la rivalidad entre las grandes potencias, se convirtió en víctima de la agresión de pequeñas potencias.

Como puede colegirse más bien tentativamente de los pocos ejemplos dados, las potencias medias en un sistema de competen: cia múltiple pueden, en ciertas circunstancias, desempeñar un papel en la política de alto nivel, yn sea como socios posibles o de hecho, en una alianza de algunas de las grandes potencias en contra del resto, ya sea como objetos de rivalidacl entre dos o más de las grandes potencias. Sin embargo, también pueden ser clejadas a su propia suerte en cuestiones que las involucran tanto a ellas como a los pequeños Estados vecinos. En principio, se encuentran expuestas a los peligros que representan tanto las grandes potencias del sistema como-los pequeños Estados regionales, y por consiguiente se verían obligadas a encarar el desafío de cualquiera de los dos grupos. Bajo circunstancias particularmente desafortunadas, como lo demuestra la relación que existía entre Rusia y sus clientes eslavos, en la región balcánica, durante los años precedentes a la Primera Guerra Mundial, los enemigos superiores e inferiores pueden cooperar $y$ buscar conjuntamente la derrota o destrucción de la potencia media.

Siempre teniendo presente que la política internacional en la década de 1980 podría ser de tipo múltiple, con quizás cuatro o más superpotencias girando alrededor de los polos de un acuerdo estrecho y una competencia hostil, los diversos papeles posibles de las potencias medias en tal orden de cosas parecen ser materia de estudio ulterior. Pese a que en este trabajo el tema ha sido considerado en forma concisa y esquemática, el lugar que ocupan dichas potencias en la política global y regional del sistema múltiple bien puede resultar uno de los capitulos más interesantes, y a la vez relevantes, del estudio modemo de las potencias medias.

Finalmente, es interesante notar que la idea de las potencias medias y su aspiración de ser reconocidas como tales, generalmente se origina en épocas en que las grandes potencias se hallan estrechamente relacionadas, ya sea unidas en acuerdos o próximas al conclominio. En una u otra forma, la cuestión surgió en situaciones de gran acuerdo de la historia moderna: en Europa después de 1815, en Versalles en 1919, en los primeros años de la Liga de las Naciones, y en la etapa inicial de las Naciones Unidas. También surgió en la Confederación Germánica, cuando el clualismo austro-prusiano casi alcanzó el estado de condominio. Y las más recientes contribuciones a la teoría de las potencias medias pueden ser consideradas como fondo de las tendencias hacia el condominio de superpotencias en los años 1960, y pueden tener, asimismo, relación con 
la posibilidad de un acuerdo múltiple de potencias nucleares en las próximas clécadas.

Esta observación apunta hacia el último predicamento de las potencias medias. Para las potencias secundarias, las situaciones de acuerdo o condominio no sólo son momentos oportunos, en que los esfuerzos de las grandes potencias por reorganizar la sociedad internacional e introducir un nuevo sistema de políticas, les podría ofrecer una oportunidad para proyectarse $y$ obtener un reconocimiento especial. También son situaciones de peligro potencial en que la preponderancia de las grandes potencias en conjunto amenaza reducirlas a la incapacidad $y$ obligarlas a luchar para asegurar sus posiciones dentro del sistema de Estaclos. Mientras que en algunas situaciones los acuerclos de las grandes potencias podrían reforzar la seguridacl de las potencias secundarias, en otras significarían un peligro para la existencia misma de dichas potencias. Los casos de Polonia en el siglo xviII y del Imperio Otomano sirven para recorclar el destino último que se depara a las potencias secundarias frente a un grupo de grandes potencias. Finalmente, una potencia media es un Estado suficientemente grande o rico para atraer la avaricia de las grandes potencias, que sin embargo no es lo bastante fuerte para repeler la usurpación de la que es víctima. 